\title{
Impact of routine hysteroscopy (HS) prior to intrauterine insemination (IUI) on pregnancy rates (PR) among infertile couples at Al-Amal Hospital, Misurata, Libya
}

\author{
Aisha M Elbareg ${ }^{1 *}$ and Fathi M Essadi ${ }^{2}$ \\ ${ }^{1}$ Associate Professor \& Senior Consultant at Al-Amal Hospital for Obs\&Gyn, Infertility treatments and Genetic Research/ Dept. of Obstetrics \& Gynecology, \\ Faculty of Medicine, Misurata University, Libya. \\ ${ }^{2}$ Senior Consultant at Dept. of Obstetrics \& Gynecology, Misurata Central Hospital, Libya.
}

\begin{abstract}
Objectives: To investigate the routine use of HS prior IUI in management of infertile women with main outcome measures studied was conception / PR.

Materials and methods: Referred 180 patients, ages: 23-38 years with similar BMI and candidate for (COH) with IUI were included in a prospective controlled study for 2 years. Hormonal evaluation for all on day 3, divided into 2 groups; (A): underwent diagnostic HS to rule out intrauterine pathology (IUP), if found operated by HS before IUI, which has to be performed following cycle if normal or 2-3 cycles after operation. (B): Control (IUI without HS). Semen collected after 5 days of sexual abstinence, prepared by swim up technique, IUI performed with $0.5 \mathrm{ml}$. Luteal support in all by oral dydrogestrone. Clinical PR: +ve pregnancy test and GS by (TVS) 4 weeks later \& compared between the two gps. Any complications were recorded. Statistical analysis by using SPSS packages for Windows. P-value significant if $(<0.05)$.

Results: out of 180 patients, 28/180 (15.5\%) patients were lost in follow up: 18 from B group leaving 72/90 (80.0\%), and 10 from A group, leaving 80/90 (88.8\%). HS revealed no pathology in (58.8\%), while (41.1\%) were with abnormalities: (15.57\%) mild adhesions, (8.86\%) small endometrial polyps, (6.64\%) small submucosal myomas, (4.46\%) uterine septum, (3.34\%) endocervical lesions, (2.21\%) chronic non-specific endometritis, (abnormalities more in women aged $\geq 30$ years and those with secondary infertility). No statistical difference in patient characteristics among groups. Pregnancy \& pathology type relationship not significant $(\mathrm{P}>0.623)$. Compared clinical PR in both gps after IUI was statistically significant $(\mathrm{P}<0.05): 37 / 80(46.25 \%)$ in HS group, and 18/80 (25\%) in control group. All pregnancies in HS group occurred within first 2 IUI cycles. No significant reactions or surgical complications were recorded.
\end{abstract}

Conclusions: HS before IUI is an effective and safe procedure in management of IUP, it improves significantly the chances of conception in infertile women before proceeding to more sophisticated and expensive treatment options.

\section{Introduction}

The evaluation of the uterine capacity for reproduction is an important step during infertility work-up, either during initial assessment or when any ART procedure is scheduled. Abnormal uterine findings are encountered in about $50 \%$ of women with reproductive failure. These high percentages of benign abnormalities are thought to be associated with poor endometrial receptivity affecting embryo implantation and necessitate proper evaluation of uterine cavity [1-5].

Currently, the gold standard technique for evaluation of the uterine cavity is HS, since it enables direct visualization of the uterine cavity and its relevant pathological disorders as well as the treatment of any detected abnormality in the same setting, unlike other indirect and purely diagnostic technique such as transvaginal sonography (TVS), hysterosalpingography (HSG), and saline infusion sonography (SIS) [611]. Nevertheless, the use of HS as a routine procedure in the infertility work-up is still under debate and there is no consensus on its efficacy and effectiveness in improving the prognosis of infertile couples [12]. On the other hand, the prolonged time to pregnancy is becoming a crucial issue in the infertility work-up due the dramatic increase in the mean age of women who attempts spontaneous conception and
ART treatments [13]. As a result, the role of HS in the diagnosis and treatment of uterine factors and its role in improving the pregnancy outcome has been re-evaluated.

Many studies have been conducted to assess the effects of diagnostic and operative HS on pregnancy rate compared with no intervention in women with otherwise unexplained infertility attempting spontaneous pregnancy or prior to IUI and intra-cytoplasmic sperm injection (ICSI) cycles. These studies revealed that the prevalence of unsuspected intrauterine abnormalities diagnosed by HS in women undergoing first ART attempt and in women with known ART failure were $18-50 \%$ and $40-43 \%$ respectively $[11,14-16]$. Also, the pregnancy rate was improved upon correction of the pathology found [17-19].

Correspondence to: Aisha M Elbareg, Associate Professor \& Senior Consultant at Al-Amal Hospital for Obs\&Gyn, Infertility treatments and Genetic Research/ Dept. of Obstetrics \& Gynecology, Faculty of Medicine, Misurata University, Libya; Tel: 00218914213607; E-mail: elbaregsm@hotmail.com

Key words: hysteroscopy, intrauterine pathology, intrauterine insemination

Received: October 08, 2017; Accepted: November 01, 2017; Published: November 04, 2017 
The advantages of IUI treatment were early recognized and applied for the treatment of patients with mild male factor, cervical or coital factor, or unexplained infertility reasons [20,21]. Its utilization has increased in the recent decades because it is a simple, non-invasive, and a cost-effective technique compared to other ART procedures [22]. To increase the success rate of IUI, it has been performed generally in combination with controlled ovarian hyperstimulation $(\mathrm{COH})$ using Clomiphene citrate or Gonadotropin or their combination $[23,24]$. The aim of this study was to assess the diagnostic and therapeutic value of HS in primary assessment before IUI in infertile couples with the main outcome measure studied was conception / PR.

\section{Material and methods}

This is a prospective controlled study carried out for two years (April 2015 to March 2017) at the fertility Unit of Al-Amal hospital for Obstetrics \& Gynecology, Infertility treatments and Genetic research / Misurata-Libya. One hundred and eighty healthy women between 23 and 38 years old (with primary and secondary infertility), similar BMI and candidate for $(\mathrm{COH})$ with clomiphene citrate and gonadotropin in conjunction with IUI cycles were equally \& randomly assigned into two groups: (A) / HS group in which women underwent HS before the IUI cycle, and if no abnormal findings, IUI performed next cycle, but candidates with IUP, surgical correction has to be performed first followed by IUI three cycles later, and (B) / control group, in which women underwent IUI cycles without HS.

The Ethics Committee of Al-Amal hospital approved this study. Patient assessment included demographic information as well as medical and gynecologic histories with physical examinations, BMI and routine laboratory screening (including Pap smear, and viral serology) were performed. The inclusion criteria were male factor, healthy women but with ovulatory disorders, unexplained infertility which was diagnosed after a normal basic fertility evaluation was proved, and without sexually transmitted diseases, pelvic inflammatory diseases or pregnancy. Patients with active vaginal bleeding, hydrosalpnix, or testicular atrophy were also excluded. Patients in HS group underwent office hysteroscopy ( $3.9 \mathrm{~mm}$ outer diameter continuous flow) in the proliferative phase of the menstrual cycle using normal saline as a distension media. Hysteroscopic evaluation included assessment of cervical canal, intrauterine lesions, the endometrium and uteriotubal junction. When hysteroscopy revealed a lesion, its type, size and location were determined and treated accordingly in the same setting.

All patients in both groups underwent hormonal assays of (FSH), $(\mathrm{LH}),\left(\mathrm{E}_{2}\right),(\mathrm{TSH})$ and $(\mathrm{PRL})$ in addition to TVS on day 3 of menstrual cycle, followed by $\mathrm{COH}$ with clomiphene citrate tablets $50 \mathrm{mg}$ twice daily on days 3-7 after which HMG (75 units/day) were given. Follicular development and endometrial thickness were assessed by TVS on day 11-12 of the menstrual cycle; if follicles found to be $18-20 \mathrm{~mm}$, and endometrial thickness $>7 \mathrm{~mm}$, single dose of HCG was given to induce the final stage of maturation and the insemination procedure was performed 36-38 hours later (The ESHRE Capri Workshop Group, 2009) [25].

Semen specimens were collected after 3-5 days of sexual abstinence and prepared using the swim-up technique. IUI was performed by a soft catheter (Kitazato, Spain) with an insemination volume of $0.5 \mathrm{ml}$, it was passed gently through the cervical canal until the tip passed the internal os, then the sperm suspension was deposited slowly through the uterine cavity. All patients provided with luteal support using oral dydrogestrone, 10mg twice per day for two weeks, as it has been found that dydrogestrone is associated with higher rate of pregnancy and even lower pregnancy complications [26]. Clinical pregnancy was documented by a positive pregnancy test 2 week after the insemination followed by the presence of a gestational sac visualized by transvaginal sonography (TVS) 4 weeks after IUI. Pregnancy outcome was determined and comparison of the pregnancy rate between two groups was performed. Any complications were recorded. Statistical analysis performed using SPSS packages for Windows. $\mathrm{P}$-value significant if $(<0.05)$.

\section{Results}

A total of 180 eligible healthy patients but with unexplained infertility, ovulatory disorders, mild endometriosis and mild male factor, were randomized into one of two groups. Ninety patients in each group. In the control group patients underwent IUI directly without performing HS, while those in the A group underwent HS in the cycle before IUI. If pathology was detected, IUI was performed 2-3 cycles after therapeutic HS. The two groups were almost identical in the age, BMI, type and duration of infertility, number of previous trials (Table 1).

In the HS group, uterine abnormalities were found in 37/90 (41.1\%) patients while the remaining 53/90 (58.8\%) were with no pathology detected. The most common abnormalities detected were mild endometrial adhesions: 14/90 (15.5\%), followed by small endometrial polyps $8 / 90(8.8 \%)$, submucous myoma $6 / 90(6.6 \%)$, short uterine septum 4/90 (4.4\%), endocervical lesions $3 / 90$ (3.3\%), and chronic nonspecific endometritis in 2/90 (2.2\%) patients (Figure 1).

During the follow up, out of 180 patients $(28 / 180,15.5 \%)$ patients were lost in both groups; $(18 / 90,20.0 \%)$ in the control group leaving (72/90, 80.0\%) with 110 IUI cycle for analysis, while in the HS group (10/90, 11.1\%) were lost, leaving $(80 / 90,88.9 \%)$ with 100 IUI cycle for analysis. Thirty-four patients with hysteroscopic surgery and 46 patients with diagnostic hysteroscopy.

Regarding the pregnancy outcome, in the control group, the overall pregnancy rate was $(18 / 72,25.0 \%)$, abortion rate was $(6 / 72$, $8.3 \%)$, and ongoing pregnancy rate was $(12 / 72,16.6 \%)$. Whereas in HS group, the overall pregnancy rate was $(37 / 80,46.25 \%)$, abortion rate was $(7 / 80,8.75 \%)$, and ongoing pregnancy rate was $(30 / 80,37.5 \%)$. The difference between the two groups was statistically significant $(P<0.05 \%)$. The pregnancy outcome was further improved when the intrauterine pathology was detected and removed by hysteroscopy (Figure 2). No complications were encountered with any of the operative hysteroscopies performed. Patients with chronic non-specific endometritis which was confirmed by histopathological examinations; treated with Doxycycline 100mg twice daily for 10 days.

Table 1. Comparison of characteristics of patients in two groups.

\begin{tabular}{|l|l|l|}
\hline Parameter & Control group (no:90) & HS group (90) \\
\hline Age (years) Mean \pm SD & $24.1 \pm 4.2$ & $24.4 \pm 5.1$ \\
\hline BMI mean \pm SD & $25.4 \pm 3.6$ & $25.1 \pm 2.5$ \\
\hline Duration of infertility (years) & $4.5 \pm 3.2$ & $5.6 \pm 4.6$ \\
\hline $\begin{array}{l}\text { Etiology of infertility } \\
\text { (Excluding lost in follow-up) }\end{array}$ & $52(72.2 \%)$ & \\
- Unexplained & $17(23.6 \%)$ & $50(62.5 \%)$ \\
- Mild male factor & $3(4.1 \%)$ & $23(28.7 \%)$ \\
- Mild endometriosis & & $7(8.7 \%)$ \\
\hline $\begin{array}{l}\text { Type of infertility } \\
\text { - Primary }\end{array}$ & $63(70.0 \%)$ & \\
$\bullet$ & $27(30.0 \%)$ & $66(73.3 \%)$ \\
\hline
\end{tabular}




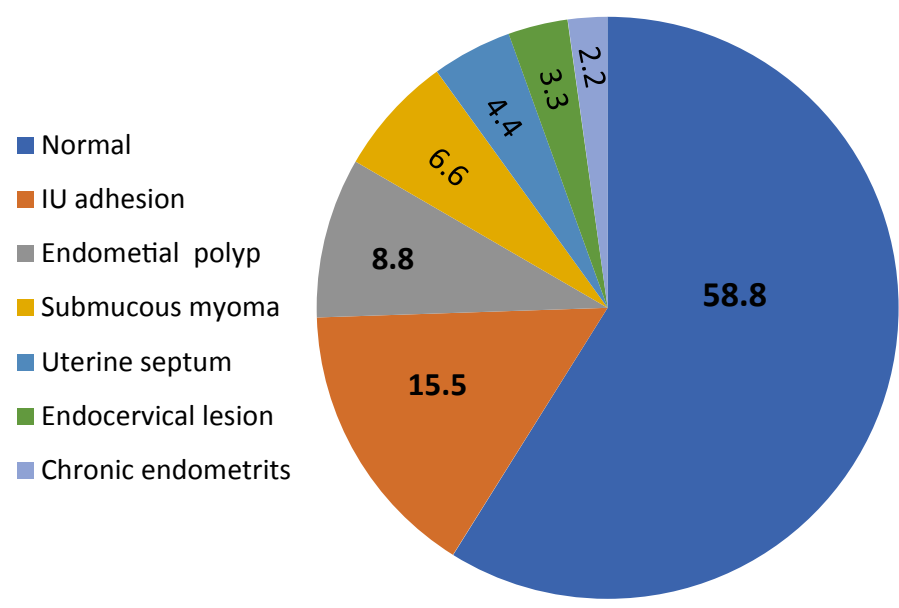

Figure 1. Hysteroscopic findings in HS group. No:90, \%

\section{Discussion}

Uterine abnormalities are estimated to play a causal role in a substantial number of couples seeking infertility treatment and in women with recurrent pregnancy losses $[27,28,4,5]$. Their assumed pathophysiological mechanism that they impair proper embryo implantation and growth due to poor vascularization with subsequent infertility or miscarriages [28]. Office Hysteroscopy is an accurate and less invasive method for the evaluation of uterine cavity. It is dynamic test and allows a direct visualization of the endometrium, revealing the nature of the pathology. In addition, hysteroscopy allows treatment of the pathology in the same setting.

In the present study, uterine abnormalities were detected in $41.11 \%$ of patients subjected to hysteroscopy. This was in agreement with results found in previous studies conducted on women with unexplained infertility, before IUI and IVF cycles which revealed that the prevalence of unsuspected intrauterine abnormalities, diagnosed by hysteroscopy was in the range of $11 \%-45 \%[14,16,29,8,10,30]$. The most common abnormality was intrauterine mild adhesions (15.5\%), followed by small endometrial polyps (8.8\%), submucous myoma (6.64\%), short uterine septum (4.4\%), endocervical lesions (3.34\%), and chronic nonspecific endometritis (2.2\%). Although the role of these subtle lesions as a cause of infertility is debatable, hysteroscopic assessment and treatment of any abnormalities detected has improved the clinical pregnancy rate, live birth rate, and cost-effective. In our study, the overall pregnancy rate in HS group was (46.25\%) whereas in control group the overall pregnancy rate $(25 \%)$, the difference was statistically significant (Figure 2). The abortion rate was similar in both groups, in HS group was $(8.7 \%)$ compared to that in the control group (8.3\%) (Figure 2). Previous studies also showed that pregnancy rate was improved when hysteroscopy was performed, and uterine abnormalities were corrected $[16,17,29,30]$. There have been a plausible explanation for the improved pregnancy outcome after hysteroscopy. Firstly, hysteroscopy reveals and treat hidden intrauterine pathology in patients with normal USS or HSG findings. Secondly, even in absence of intrauterine pathology, it has been demonstrated that an increase in level of glycodelin which is a endometrium-derived protein, present in both plasma and uterine flushing's and implicated in the process of implantation and angiogenesis is produced significantly by growing tumors such as leiomyomas and polyps as uterine glycodelin flushings are found elevated in patients with these pathology. Elevated glycodelin levels in the follicular and peri-ovulatory period may impair fertilization and implantation, therefore, it has been proposed that irrigation of the cavity with saline, mechanically removes these harmful anti-adhesive molecules found on the endometrial surface and involved in endometrial receptivity [31]. In addition, the diagnostic hysteroscopy itself may allow easier IUI or embryo transfer due to the passage of the tip of hysteroscopy through the cervical canal with the contemporaneous lysis of cervical adhesions $[32,10]$.

Contrary to the above mentioned initiative results, some research found that the hysteroscopic surgery was associated with a high prevalence of complications, i.e., uterine perforation, injury to bladder and bowel, excess bleeding, infection, haemodilution by absorption of distension media, resulting in hyponatremia leading to respiratory distress, pulmonary oedema as well as cardiovascular collapse, and even death $[33,34]$. However, in our study, diagnostic hysteroscopy and operative procedures were carried out smoothly with great success and without any particular difficulty, and to avoid pain which usually resembling menstrual cramps that might be experienced by some patients, especially during the passage of the tip of the hysteroscopy through the internal cervical ostium, we followed a simple protocol just by placing misoprostol $400 \mu \mathrm{g}$ vaginally 4 hours before starting the procedure to enhance cervical priming [35]. Neither intracervical injection of anesthesia nor IV sedation was used.

\section{Conclusion}

Our present study along with the previous studies provide a strong evidence for including hysteroscopy as part of the primary investigation of infertile couple and couples undergoing ART. It is the golden tool in the management of detected intra-uterine pathology, as it allows direct visualization of uterine cavity and this particularly confer it a high diagnostic accuracy, that associated to the possibility of simultaneous treatment of intrauterine diseases. IUI is an effective, safe and reliable procedure, it improves significantly the chances of conception in infertile women before proceeding to more sophisticated and expensive treatment options. As the application of hysteroscopy in ART is rapidly evolving, many areas relating to this procedure require more intensive research to enable the adoption of best practice in management of patients in need of assisted reproduction.

\section{Conflicts of interest}

The authors declare that they have no conflicts of interest related to the subject matter or materials discussed in this article.

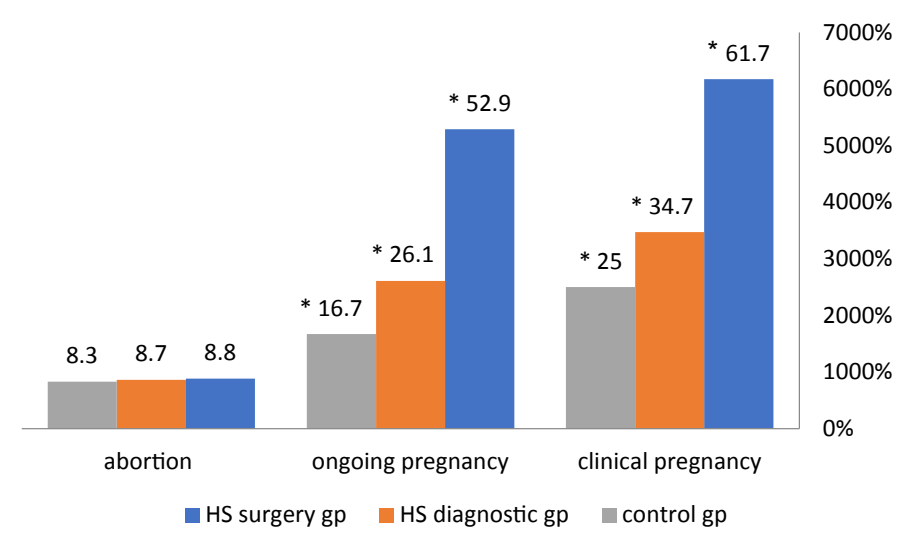

Figure 2. Pregnancy outcome in the study groups: HS surgery group, no:34, HS diagnostic group, no:46, control group, no: 72 . * $\mathrm{P}<0.05$ statistically significant 
Elbareg AM (2017) Impact of routine hysteroscopy (HS) prior to intrauterine insemination (IUI) on pregnancy rates (PR) among infertile couples at Al-Amal Hospital, Misurata, Libya

\section{Financial disclosure}

The authors declared that this study has received no financial support.

\section{Author contributions}

AME- designed the study, data collection, conducted the clinical work and writing Manuscript. FME- conducted the Literature Search, statistical analyses/Interpretation, and critical review. All authors approved the final manuscript.

\section{Acknowledgments}

The authors would like to thank the staff members of Al-Amal Hospital IVF Centre for their kind cooperation as well as all included patients for the valuable contribution in this work.

\section{References}

1. Hornemann A, Luedders DW, Kumbartski M (2009) Anatomic disorders as a reason for recurrent miscarriages. Gynakologe 42: 11-16.

2. Revel A (2012) Defective endometrial receptivity. Fertil Steril 97: 1028-1032. [Crossref]

3. NICE. Fertility: Assessment and Treatment for People with Fertility Problems. National Institute for Health and Clinical Excellence.

4. Elbareg AM, Essadi FM, Elmehashi MO, Anwar KI, Adam I (2014) Hysteroscopy in Libyan women with Recurrent Pregnancy Loss. Sudan JMS 9: 239-244.

5. Elbareg AM, Essadi FM, Anwar KI, Elmehashi MO (2014) Value of hysteroscopy in management of unexplained infertility. Asian Pacific Journal of Reproduction 3: 295-298.

6. Bettocchi S, Ceci O, Di Venere R, Pansini MV, Pellegrino A, et al, (2002) Advanced operative office hysteroscopy without anesthesia: analysis of 501 cases treated with a 5 Fr. bipolar electrode. Hum Reprod. 17: 2435-2438. [Crossref]

7. Di Spiezio Sardo A, Bettocchi S, Spinelli M, Guida M, Nappi L, et al, (2010). Review of new office-based hysteroscopic procedures 2003-2009. J Minim Invasive Gynecol 17: 436-448. [Crossref]

8. Shawki HE, Elmorsy M, Eissa MK (2012). Routine office hysteroscopy prior to ICSI and its impact on assisted reproduction program outcome: a randomized controlled trial. Middle East Fertil Soc J 17: 14-21.

9. Kasius JC, Eijkemans RJ, Mol BW, Fauser BC, Fatemi HM, et al. (2013) Costeffectiveness of hysteroscopy screening for infertile women. Reprod Biomed Online 26: 619-626. [Crossref]

10. Elsetohy KA, Askalany AH, Hassan M, Dawood Z (2015) Routine office hysteroscopy prior to ICSI vs. ICSI alone in patients with normal transvaginal ultrasound: a randomized controlled trial. Arch Gynecol Obstet 291:193-199. [Crossref]

11. Bakas P, Hassiakos D, Grigoriadis C, Vlahos N, Liapis A, et al. (2014) Role of hysteroscopy prior to assisted reproduction techniques. J Minim Invasive Gynecol 21: 233-237. [Crossref]

12. Di Spiezio Sardo A, Di Carlo C, Minozzi S, Spinelli M, Pistotti V, et al,(2016) Efficacy of hysteroscopy in improving reproductive outcomes of infertile couples: a systematic review and meta-analysis. Hum Reprod Update 22: 479-496. [Crossref]

13. Munné S, Held KR, Magli CM, Ata B, Wells D, et al. (2012). Intra-age, intercenter, and intercycle differences in chromosome abnormalities in oocytes. Fertil Steril 97: 935-942. [Crossref]

14. Demirol A, Gurgan T (2004) Effect of treatment of intrauterine pathologies with office hysteroscopy in patiets with in recurrent IVF failure. Reprod Biomed Online 8: 590594. [Crossref]

15. Bozdag G, Aksan G, Esinler I, Yarali H (2008) What is the role of office hysteroscopy in women with failed IVF cycles? Reprod Biomed Online 17: 410-415. [Crossref]

16. Fatemi HM, kasius JC, Timmermans A, van Diosseldorp J, Fauser BC, et al. (2010). Prevalence of unsuspected uterine abnormalities diagnosed by office hysteroscopy prior to in vitro fertilization. Hum Reprod 25: 1959-1965. [Crossref]

17. Makrakis E, Pantos K (2010) The outcomes of hysteroscopy in women with implantation failure after in-vitro fertilization: findings and effec on subsequent pregnancy rates. Curr Opin Obstet Gynecol 22: 339-343. [Crossref]
18. Karayalcin R, Ozcan S, Moraloglu O, Ozyer S, Mollamahmutoglu L, et al. (2010) Results of 2500 office-based diagnostic hysteroscopies before IVF. Reprod Biomed Online 20: 689-693. [Crossref]

19. Shohayeb A, El-Khayat W (2012). Does a single endometrial biopsy regimen (S-EBR) improve ICSI outcome in patients with repeated implantation failure? A randomized controlled trial. Eur J Obstet Gynecol Reprod Biol 164: 176-179. [Crossref]

20. Ibérico G, Vioque J, Ariza N, Lozano JM, Roca M, et al. (2004). Analysis of factors influencing pregnancy rates in homologous intrauterine insemination. Fertil Steril 81: 1308-1313. [Crossref]

21. Honda T, Tsutsumi M, Komoda F, Tatsumi K (2015) Acceptable pregnancy rate of unstimulated intrauterine insemination: a retrospective analysis of 17,830 cycles. Reprod Med Biol 14: 27-32. [Crossref]

22. Cohlen BJ (2009). Should luteal phase support be introduced in ovarian stimulation IUI programmes? An evidence-based review. Reprod Biomed Online; Suppl 4: 4239. [Crossref]

23. Kossakowski J, Stephenson M, Smith H (1993). Intrauterine insemination with husband's sperm: comparison of pregnancy rates in couples with cervical factor, male factor, immunological factor and idiopathic infertility. Aust N Z J Obstet Gynaecol 33 : 183-186. [Crossref]

24. Miralpeix E, González-Comadran M, Solà I, Manau D, Carreras R, et al. (2014) Efficacy of luteal phase support with vaginal progesterone in intrauterine insemination: a systematic review and meta-analysis. J Assist Reprod Genet 31: 89-100. [Crossref]

25. ESHRE Capri Workshop Group1 (2009) Intrauterine insemination. Hum Reprod Update 15: 265-277. [Crossref]

26. Zainul Rashid MR, Lim JF, Nawawi NH, Luqman M, Zolkeplai MF, et al. (2014) A pilot study to determine whether progestogen supplementation using dydrogestrone during the first trimester will reduce the incidence of gestational hypertension in primigravidae. Gynecol Endocrinol 30: 217-220.

27. Propst AM, Hill JA 3rd (2000) Anatomic factors associated with recurrent pregnancy loss. Semin Reprod Med 18: 341-350. [Crossref]

28. Brown SE, Coddington CC, Schnorr J, Toner JP, Gibbons W, et al. (2000) Evaluation of outpatient hysteroscopy, saline infusion hysterosonography, and hysterosalpingography in infertile women: a prospective, randomized study. Fertil. Steril 74: 1029-1034. [Crossref]

29. Moramezi F, Barati M, Mohammedjafari R, Barati S, Hemadi M (2012). Effect of hysteroscopy before intrauterine insemination on fertility in infertile couples. Pak $J$ Biol Sci 15: 942-946. [Crossref]

30. Alleyassin A, Abiri A, Agha-Hosseini M, Sarvi F (2017) The Value of Routine Hysteroscopy before the First Intracytoplasmic Sperm Injection Treatment Cycle. Gynecol Obstet Invest 82: 125-130. [Crossref]

31. Takahashi K et al., (2000). High pregnancy rate after hysteroscopy with irrigation in uterine cavity prior to blastocyst transfer in patients who have failed to conceive after blastocyst transfer. Fertil Steril 74: 206.

32. Dhulkotia J, Coughlan C, Li TC, Ola B (2012). Effect of endometrial injury on subsequent pregnancy rates in women undergoing IVF after previous implantation failure: systematic review and meta-analysis. Hum Reprod 27: ii66-ii67

33. Pasini A, Belloni C (2001). Intraoperative complications of 697 consecutive operative hysteroscopies. Minerva Ginecol 53: 13-20 [Crossref]

34. Bradley LD1 (2002) Complications in hysteroscopy: prevention, treatment and legal risk. Curr Opin Obstet Gynecol 14: 409-415. [Crossref]

35. Elbareg AM, E Sirkasi MO, Essadi FM, et al., (2015). Vaginal Misoprostol for Cervical Priming before Operative Hysteroscopy in Misurata Hospital, Libya. Sudan Journal of Medical Sciences 10: 53-58.

Copyright: (C2017 Elbareg AM. This is an open-access article distributed under the terms of the Creative Commons Attribution License, which permits unrestricted use, distribution, and reproduction in any medium, provided the original author and source are credited. 